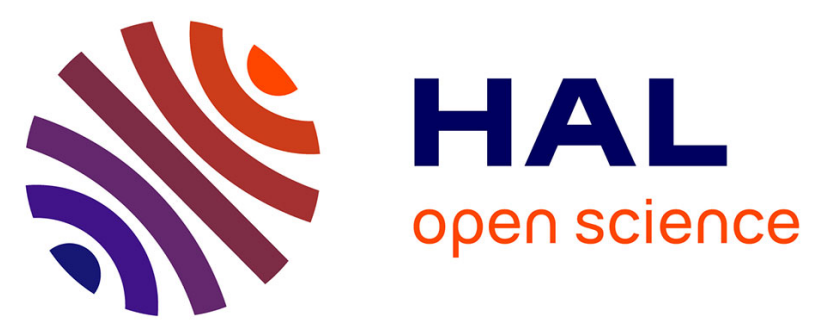

\title{
RELATIVE ENERGY DIAGRAM OF THE LOWEST UNOCCUPIED MOLECULAR ORBITALS OF OXO-, THIO- AND SELENO-VANADIUM (IV) PORPHYRINS, AS INFERRED FROM COMBINED XANES AND ESR DATA
}

M. Ruiz-Lopez, D. Rinaldi, C. Esselin, J. Goulon, J. Poncet, R. Guilard

\section{To cite this version:}

M. Ruiz-Lopez, D. Rinaldi, C. Esselin, J. Goulon, J. Poncet, et al.. RELATIVE ENERGY DIAGRAM OF THE LOWEST UNOCCUPIED MOLECULAR ORBITALS OF OXO-, THIO- AND SELENOVANADIUM (IV) PORPHYRINS, AS INFERRED FROM COMBINED XANES AND ESR DATA. Journal de Physique Colloques, 1986, 47 (C8), pp.C8-637-C8-640. 10.1051/jphyscol:19868120 . jpa00226019

\section{HAL Id: jpa-00226019 https://hal.science/jpa-00226019}

Submitted on 1 Jan 1986

HAL is a multi-disciplinary open access archive for the deposit and dissemination of scientific research documents, whether they are published or not. The documents may come from teaching and research institutions in France or abroad, or from public or private research centers.
L'archive ouverte pluridisciplinaire HAL, est destinée au dépôt et à la diffusion de documents scientifiques de niveau recherche, publiés ou non, émanant des établissements d'enseignement et de recherche français ou étrangers, des laboratoires publics ou privés. 


\title{
RELATIVE ENERGY DIAGRAM OF THE LOWEST UNOCCUPIED MOLECULAR ORBITALS OF OXO-,THIO- AND SELENO-VANADIUM (IV) PORPHYRINS, AS INFERRED FROM COMBINED XANES AND ESR DATA
}

\author{
M.F. RUIZ-LOPEZ* , D. RINALDI* C. ESSELIN* , \\ J. GOULON*,**, J.L. PONCET ${ }^{* * *}$ and R. GUILARD*** \\ * Laboratoire de Chimie Théorique, U.A. 510 CNRS, Université \\ de Nancy I, BP 239, F-54506 Vandoeuvre-Ies-Nancy Cedex, \\ France \\ * LURE, L.P. CNRS, MEN, CEA, Université de Paris-Sud, \\ Bâtiment 209D, F-91405 Orsay Cedex, France \\ ** Laboratoire de Synthèse et Electrosynthèse, U.A. 33 CNRS, \\ Faculté des sciences Gabriel, 6, Boulevard Gabriel, \\ F-21100 Dijon, France
}

\begin{abstract}
Sommaire
Les spectres XAlES des porphyrines d'oxo- thio- et seleno-vanadium (IV) ainsi que les mesures de RPE de ces composés ont été utilisés pour etudier le diagrame d'energie des orbitales moleculajres à caractère 3d. Nous examinons la possibilité de déduire une valeur approchée de la constante de couplage spin-orbite à partir de ces donnés experimentales et des résultats des calculs théoriques.

\section{Abstract}

The XAMES spectra of oxo- thiom and seleno-vanadiun (IV) porphyrins together with ESR measurements on these compounds have been used to study the enerey diagram of the 3j-l1ke molecular orbitals. Possibilities for extracting an approximate value of the spin-orbit coupling constant ace discussed on the basis of experimental data and theoretical results.
\end{abstract}

\section{Introduction}

The Vanadiun K-edge spectra of oxo- thio- and seleno-vanadyl porphyrins all exhibit a well resolved preedge white line, but quite significant shifts of the position of this pre-peak and of its intensity can be measured. Considering the symmetry of these systems $\left(C_{4}\right.$ group $)$ and consistent with a formal metal oxidation state $I V$, the preedge lines car be assigned to electronic transitions from the metal is core level to $3 \mathrm{~d}-1 \mathrm{ike}$ molecular orbitals (M.O.) of symmetry $a_{l}$ and $e$. Thus, the observed shifts in Xares show that significant energy variations of the metal $3 d$ levels exist tithin the present sepies of compounds.

Relative variations of 3d-like M.Q. of symetry $b_{1}$ and $e$ have also been detected from careful ESR studies of these d metalloporphyrins[1]. However, in this case the determination of the absolute energy shifts requires an estimation of the spin-orbit coupling constant $\xi$, which $1 s$ usually interpolated using the metal net charge and atomic calculations of $\xi$. 
Conversely, the observed shifts in XANES could be used to extract an approximate value of $\xi$ to be used for analyzing ESR data, provides one is able to account for orbital relaxation effects after the creation of deep core hole in XAIES.

In this work, we try to correlate XANES and ESF data with the help of theoretical calculations using the unrestricted Hatree-Fock INMo/S method [2] and the $\mathrm{Xr}$ scattered-wave approximation [3].

\section{Experimental data}

\section{XANES spectra}

The XANES spectra of $2,3,7,8,12,13,17,18$ octaethylporphyrinato -oxo and -thio vanadium (IV) complexes $D \mathrm{~g}: \mathrm{V}=\mathrm{X}(\mathrm{X}=0.3)$ are reproduced in figure la, the corresponding edge first derivatives being shown in figure $1 \mathrm{~b}$. These spectra were recorded at LURE on the EXAFS-II station operating in the conventional absorption mode. The spectra of the oxo and seleno derivatives are also compared in figures 1c/1d. Due to the strong absorbance of the selenovarialyl compound. these data were recorded in the $x$-ray fluorescence mode. The quality
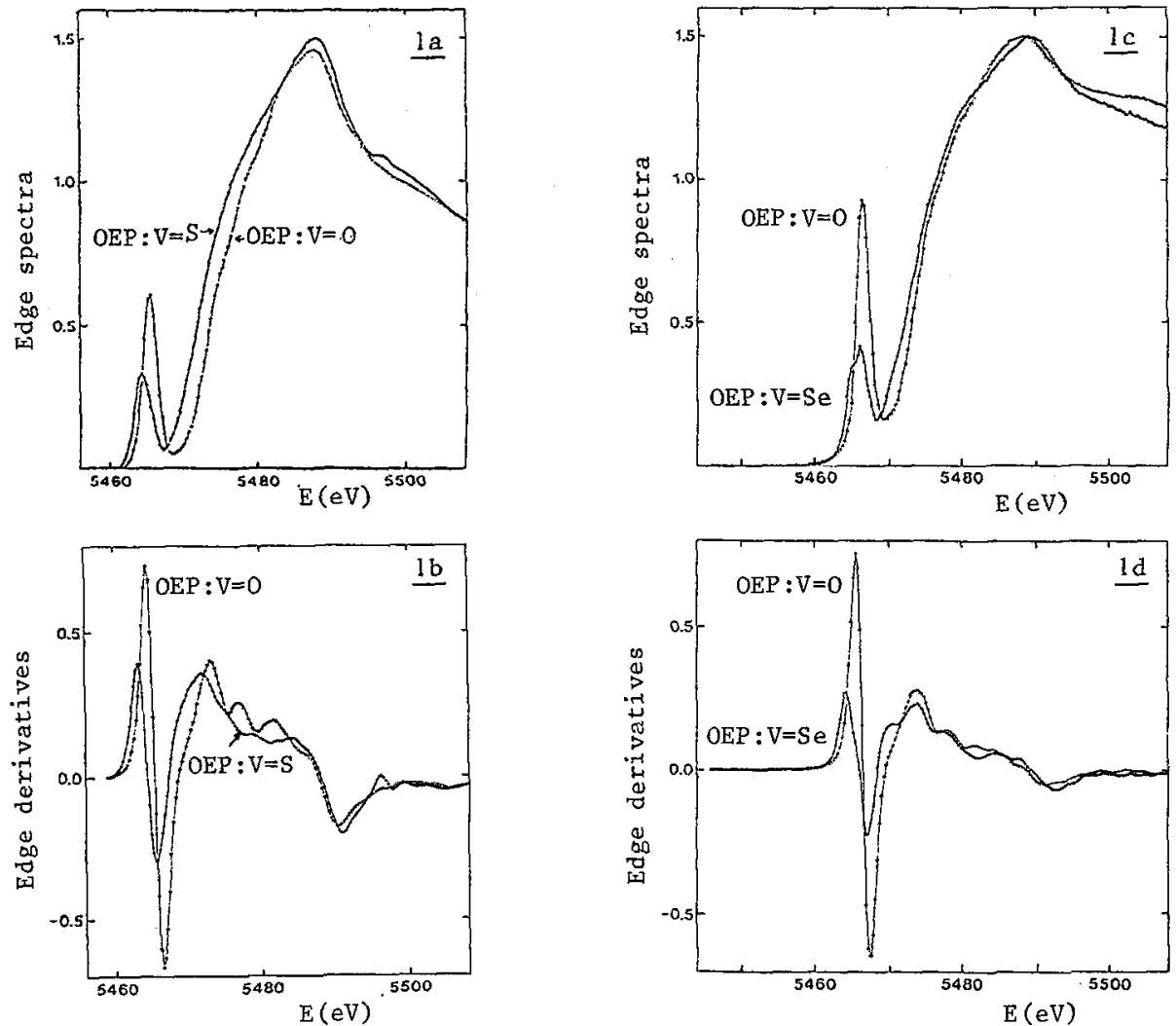

Figure 1 : XANES spectra of the series $O E P: V=X \quad(X=0, S, S e)$

Comparison of edge_spectrra : la) $X=S$ v.s. $X=0$

lc) $x=\operatorname{se} v \cdot s . x=0$

Comparison of the edgefírst derivatives : 1b) $X=S$ v.s. $X=0$

ld) $X=$ Se v.s. $X=0$ 
and the resolution of the later spectra were also improved by the use of an efficlent two mirror harmonic rejector. It is clear from figures 1a (1c) that the prepeak of the thio- (seleno-) derivative is silghtly shifted towards lower energies with respect to the prepeak of 0 EP: $V=0$ by $\Delta E=1.0$ eV $\{1.2 \pm 0.2$ eV).

\section{ESR measurements}

The morphology of the ESR spectra of these compounds is characteristic of Vanadium (IV) complexes having a single $3 d$ electron. Considering the symmetry of the systems, one concludes that the electronic ground state has a configuration $\left(b_{2}\right)^{1}, b_{2}$ being a M.O. with a strong contribution of the metal $d_{x} 2_{-}{ }^{2}$ orbital. For these axially symetrical compounds, the anisotropic $g$ tensor $1 \mathrm{~s}$ defined by $1 \mathrm{ts}$ two components $\mathrm{g}^{\prime \prime}$ and $\mathrm{g}^{+}$, easily determined from powder EPR spectra. Due to spln-orbit coupling $\xi$, these factors become related to the energy differences of the M.O., $\Delta^{\prime \prime}=\varepsilon_{b_{1}}-\varepsilon_{b_{2}}$ and $\Delta^{\perp}=\varepsilon_{e}-\varepsilon_{b_{2}}$, according to:

$\Delta^{\prime \prime} / \alpha^{2}=2 \delta^{2} E\left(B_{e}-B^{\prime \prime}\right)$

$\Delta^{\perp} / \gamma^{2}=2 \delta^{2} \quad E\left(B_{e}-g^{\perp}\right)$

where $\alpha, \gamma$ and $\delta$ are the coefficients of the metal $3 d$ orbitals in the M.O. of symmetry $b_{1}$, $\theta$ and $b_{2}$ respectively. The last one corresponds to the $d_{x y}$ orbital so that one may consider $\delta \cong 1$. On the other hand, the spin-orbit coupling constant may be estimated to be $\xi=170 \mathrm{~cm}^{-1}$ by assuming $a V^{2}$ charge [1]. These considerations lead to $\Delta^{\prime \prime} / \alpha^{2}=4.2,4.4,5.3 \mathrm{eV}$ and $\Delta^{1} / \gamma^{2}=2.4$, $1.4,0.7$ eV for OEP:VO, OEP:VS and OEP:VSe respectiveIy. From previous EH calculations [4] one has $\alpha \cong 0.95$ and $\gamma \approx 0.91$ so that one estimates $\Delta_{0 \text { Ep-vo }}^{\prime \prime}$ $\Delta_{\mathrm{DEP}-U S}^{\prime \prime}=0.18 \mathrm{eV}$ and $\Delta_{0 E P-V_{0}}^{1}-\Delta_{0 E P-U S}^{1}=0.8 \mathrm{eV}$. Making the hypothesis that the $b_{2}$ levels have almost the same energy in these compounds, the last value gives approximatively the shift between the e levels in OEP:VO and OEP:VS and can be compared with the observed shift in the prepeak of XANES spectra, which is leV. We notice, finally, that the variation of $\Delta^{\prime \prime}$, which depends on the metal-macroeycle interaction, Is correlated with the metal to plane distance determined with EXAFS which decreases from OEP:VO to OEP:VSe [1].

\section{Theoretical calculations}

We have performed unrestricted Hartree-Fock INDO/S calculations for OHP:VO and $\mathrm{DBP}$ :VS in their electronic ground states. The 3d-11ke M.0. obtained are plotted in Figure 2. The energy of the singly occupled b orbital is a spinaverage of the calculated $\alpha$ and $B$ levels, so that it approximatively follows Koopman's theorem [2]. From the figure, one sees that the $b_{1}$ and $b_{2}$ orbitals have almost the same energy in both compounds. On the contrary, the orbitals $a_{1}$ and $\theta$ are more stabilised in the case of OEP:VS by $1.2 e V$ and $0.8 \mathrm{eV}$ respectively. The value of the shift predicted by our theoretical calculations for the orbital e corresponds exactly to the observed shift in $\Delta$. For the orbital $b_{2}$ our results do not predict 2 significant shift, and, in fact, the variation of $\triangle$ observed in ESR is rather small. One notices also that the position of the M.O, $a_{1}$, which $1 \mathrm{~s}$ not detected in ESR, is not far from that of the M.O. $\theta$, specially in the case of OEP:VS. This can explain why in XAFES, where both $1 \mathrm{~s} \rightarrow a_{1}$ and $1 \mathrm{~s}$ te transitions are symmetry allowed, any spliting of the white line is observed.

It is interesting to compare now these results with the energy shifts observed in XANES. In order to determine the importance of the orbital relaxation after the creation of a core hole, we have performed Xo-SW calculations for OEP:VO and OEP:VS systems. The energy separation between the - levels in the XARES flnal state $(1 \mathrm{~s}) \ldots\left(b_{2}\right)^{1}(\theta)^{1}$ is predicted to be $1 e V$, in perfect asreement with the observed shift (see Figure 1). The slightiy greater value of this energy separation compared to that obtained in ESR Is explained 


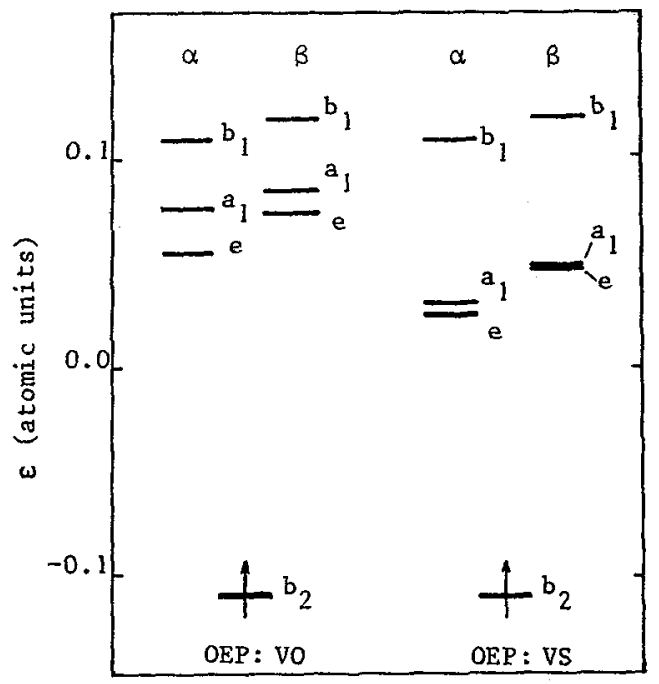

Figure 2 : Unrestricted HartreeFock INDO/S molecular orbitals of OEP: $V=O$ and $O E P: V=S$ in the electronic ground state

by considering the orbital relaxation energies. Our results predict that the difference $\varepsilon_{e}-\varepsilon_{b 2}$ decreases in the XANES final state because a greater stabilisation of the orbitals. However, the decrease is more important in the case of OEP:VS $(0.5 \mathrm{eV})$ than in the case of OEP:VO $(0.4 \mathrm{eV})$

The self-consistency of the experimental measurements and the theoretical calculations presented in this work justify the assumptions made in the discussion. In particular, the cholce of the spin-orbit coupling constant $\xi=170 \mathrm{~cm}^{-1}$ is consistent with the estimation made here for the XANES relaxation effects. More detalled calculations will be presented in a forthcoming paper (M.F. RUIZ-LOPEZ, R. NATOLI, J. GOULON, to be published).

\section{Conclusion}

The results presented in this paper show that combined XANES and ESR measurements allow to describe the $3 d-11 k e \mathrm{M}, 0$. of this kind of paramagnetic system wel1. The orbital relaxation effects in KANFS have to be taken into account if one wants to use the experimental data from both techniques to extract informations about spin-orbit coupling. While guantitative values for these relaxation effects cannot be obtained without sophisticated ab inltio techniques, we have shown that reasonable results can be deduced with a semiempirical method as INDO/S, or with methods based on the Xx approximation. $A$ more general study of these effects is now in progress (M.F. RUIZ-LOPEZ, to be published).

\section{RePerences}

[1 ]a J.L. Poncet, R. Guilard, P. Friant, C. Goulon-Ginet and J. Goulon, Nouv. J. Ch1m, B, $583(1984)$

b Proc. of the IVth Int. Conf. on the organic chemistry of Selenium and Tellurium. (1983) p. 379. @. by F.J. BERRY and W.R. MeWHININE

[2] A.D. Bacon and M.C. Zerner, Theoret. Ch1m. Acta (Berl.) 53, 21 (1979)

[3] K.H. Johnson, Adv. Quantum Chem., ?, 143 (19r3)

[4] D. Kivelson and S.K. Lee, J. Chem. Phys., 41, 1896 (1964) 